\title{
African Mole-rats (Bathyergidae): A Complex Radiation in Tropical Soils
}

\author{
Paul A. A. G. Van Daele, Chris G. Faulkes, Erik Verheyen, \\ Dominique Adriaens
}

\section{1 \\ Introduction}

African mole-rats are obligatory subterranean hystricognath rodents endemic to the Afrotropical region. The family contains solitary, social and two evolutionary divergent eusocial taxa, the naked mole-rat (Heterocephalus glaber) and the Damaraland mole-rat (Fukomys damarensis; Jarvis 1981; Jarvis and Bennett 1993; Bennett and Faulkes 2000) (but see Burda et al. 2000 who consider also other species of the genus Fukomys to be eusocial). This social diversity has lead to a great deal of recent research interest in the group, although many holotypes had been described by the late nineteenth century (reviewed by Ellerman et al. 1940, 1953). In this chapter it is our intention to review what is known about the phylogenetic relationships in Bathyergidae, with particular emphasis on the central African clade (Cryptomys/Fukomys) and present the evidence that shows how taxonomic differentiation has been influenced by past climatic and geomorphological factors. We realise that factors other than the historical geographic setting affect evolution in these subterranean rodents, including evolutionary constraints set by population demography on reproductive isolating mechanisms and enhancement of divergence through hybridisation (Golding and Strobeck 1983; Harrison 1993; Ruedi et al. 1997; Grant and Grant 1997; Steinberg and Patton 2000). At this stage, however, demographic studies and the role of hybridisation as an evolutionary mechanism have not received explicit attention in bathyergids. Data on chromosomal diversification in Fukomys, however, suggest that this genus at least may bear the stamp of reticulation events (Van Daele et al. 2004).

Paul A. A. G. Van Daele: Evolutionary Morphology of Vertebrates, Ghent University, K.L.Ledeganckstr. 35, 9000 Ghent, Belgium, E-mail: Paul.VanDaele@ugent.be

Chris G. Faulkes: School of Biological \& Chemical Sciences, Queen Mary, University of London, Mile End Road, London E14NS

Erik Verheyen: Royal Belgian Institute of Natural Sciences, Vautierstr. 29, 1000 Brussels, Belgium

Dominique Adriaens: Evolutionary Morphology of Vertebrates, Ghent University, K.L. Ledeganckstr. 35, 9000 Ghent, Belgium 


\section{2}

\section{Intergeneric Relationships}

Bathyergids have been the subject of numerous phylogenetic studies incorporating data from morphology (Wood 1985), allozyme data (Nevo et al. 1987; Filippucci et al. 1994, 1997; Janecek et al. 1992), mitochondrial restriction fragment analysis (Honeycutt et al. 1987), nuclear Transthyretin (TTR) sequence data (Walton et al. 2000), the nuclear von Willebrand Factor gene (Huchon and Douzery 2001), mitochondrial 12S rRNA (12S) (Honeycutt et al. 1987; Allard and Honeycutt 1992; Nedbal et al. 1994) and mitochondrial cytochrome b (cyt b) sequence data (Faulkes et al. 1997). Systematic overviews of the Bathyergidae by Jarvis and Bennett (1990) and Honeycutt et al. (1991) provided the basis for more recent studies on intergeneric and intrageneric relationships (Faulkes et al. 2004; Ingram et al. 2004). The Bathyergidae are the most species rich of the four monophyletic families that constitute the Phiomorpha (the African clade of Hystricomorph rodents; Nedbal et al. 1994). At the subfamilial level, groupings based on morphology are not corroborated by molecular evidence (Walton et al. 2000). The consensus now is that the family Bathyergidae consists of six extant genera (Kock et al. 2006), the highest number among subterranean rodents: Heterocephalus, Heliophobius, Bathyergus Georychus, Cryptomys and Fukomys (Fig. 27.1). Molecular genetic data unambiguously support this treatment at the generic level. All recent studies indicate that the eusocial mole-rat Heterocephalus glaber is sister to a group comprising all other genera in the family. At the next dichotomy, Heliophobius forms a sister lineage to the remaining genera. Following Faulkes et al. (2004) and Ingram et al. (2004) Georychus and Bathyergus group in a monophyletic clade, but the relationships with Cryptomys and Fukomys remain poorly resolved. Several studies have observed that Cryptomys sensu lato actually comprised two divergent clades and recommended the recognition of two separate genera (Nevo et al. 1987; Honeycutt et al. 1991; Janecek et al. 1992; Filippucci et al. 1994, 1997; Faulkes et al. 1997, 2004; Walton et al. 2000; Ingram et al. 2004). It is now generally accepted that Cryptomys sensu lato should be split into Cryptomys and the new genus Fukomys based on the reciprocal monophyly in both nuclear and mitochondrial analyses, the high level of sequence divergence between the two taxa and differential patterns of chromosomal evolution. The available data suggest that intrageneric variability, particularly in Fukomys, is higher then hitherto accepted and many new species await description (Van Daele et al. 2004). Morphological synapomorphies allow a straightforward diagnosis of Heterocephalus, Bathyergus, Georychus and Heliophobius. However, Cryptomys and Fukomys cannot be clearly separated on morphological and traditional morphometric criteria. Preliminary geometrical morphomet- 


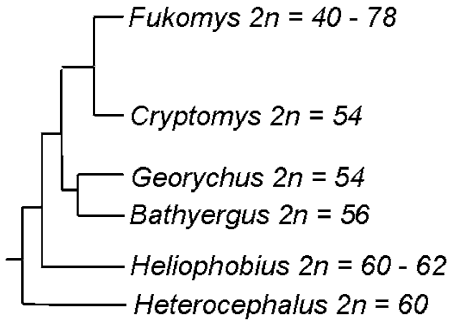

Fig. 27.1. Phylogenetic relationships of African mole-rats

rical data indicate subtle differences in skull morphology between the two genera (Van Daele et al. 2006; Van Daele, Corkery and Murtas, unpublished data).

\section{3}

\section{Biogeography of the Bathyergidae}

Recent molecular phylogenies that have inferred a molecular clock, have consistently suggested an ancient (Eocene) origin for the Bathyergidae (e.g. Huchon and Douzery 2001). Unfortunately, fossil-bearing strata of the Eocene/Oligocene are extremely rare in Africa (Lavocat 1978), and fossil bathyergids first appear later on in the more common early Miocene deposits. Of the extant genera, Heterocephalus is the first to appear in the fossil record and the temporal association of Heterocephalus fossils with extinct bathyergid ancestors supports the early divergence of Heterocephalus within the family that is suggested by molecular phylogenies (for a recent review of fossil bathyergids see Faulkes et al. 2004).

The availability of robust molecular phylogenies now enables us to infer the potential phylogeographic influences that underlie the adaptive radiation of the Bathyergidae. Molecular phylogenies of the Bathyergidae are rooted in East Africa with Heterocephalus and Heliophobius being the earliest divergences (Fig. 27.2a). Molecular clock-based timing of the major divergences within the family suggest that the initial cladogenesis of the Bathyergidae was sufficiently early to be independent of the rifting and volcanism that characterise this part of Africa today, and a general radiation appears to have occurred from East Africa into southern and south-central Africa. Divergence of the basal lineages in the Bathyergidae, Heterocephalus (40-48 mya) and Heliophobius (32-40 mya) may have been constrained northwards by the Ethiopian highlands, but was relatively unimpeded south and west (Fig. 27.2b). It has been suggested (Honeycutt et al. 1991) that these early Bathyergids may have spread via a corridor of fluctuating aridity linking east and southwest Africa (Van Zinderen Bakker 1967). This arid corridor has been implicated in the distribution of both modern 

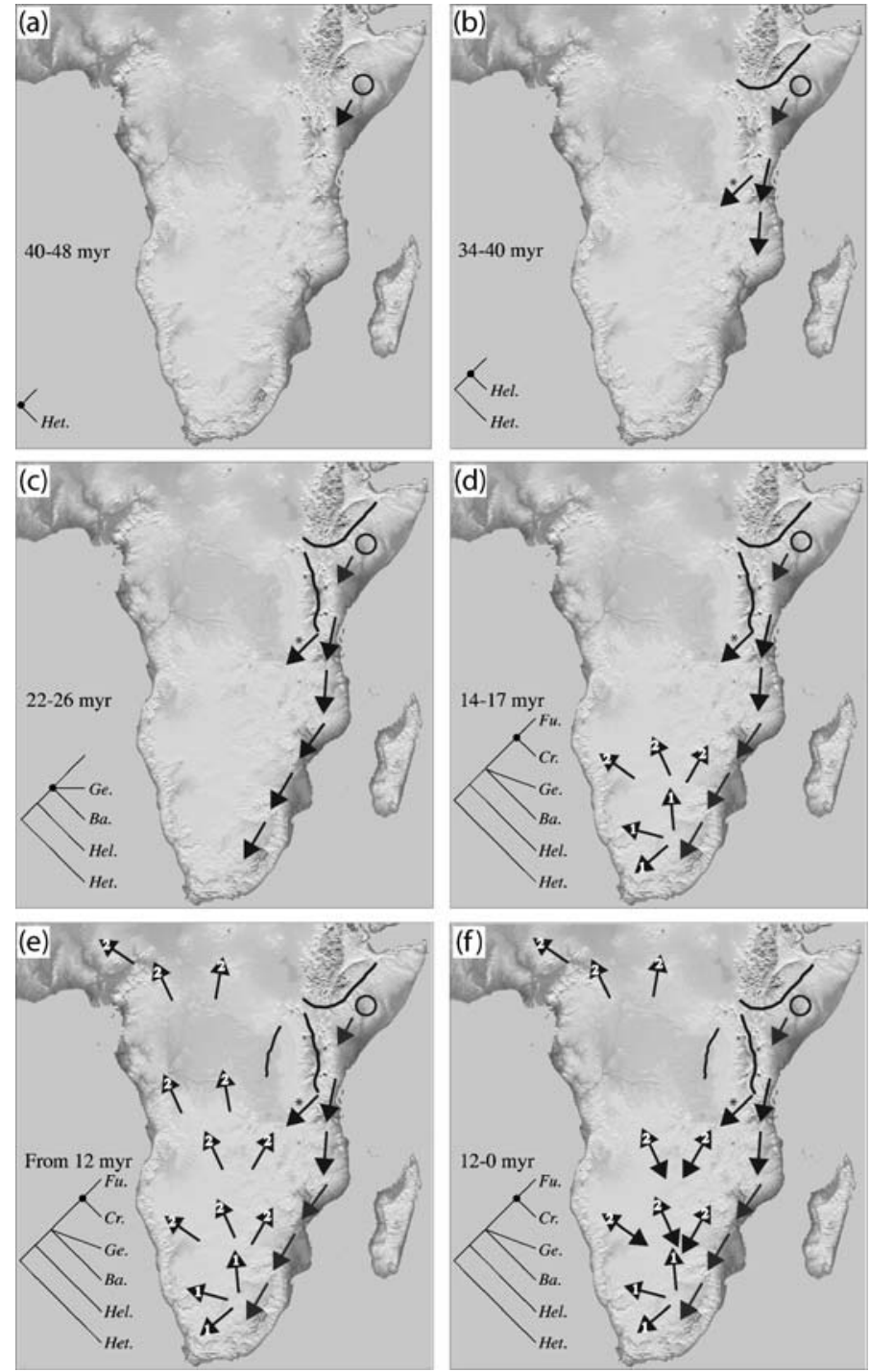

Fig. 27.2a-f. Phylogeographic trends in the Bathyergidae inferred from analysis of mitochondrial $12 \mathrm{~S}$ rRNA and cytochrome b sequence differences: a initial divergence of the Heterocephalus (Het.) lineage from the common ancestor of the family in East Africa; b radiation of Heliophobius (Hel.) and movement from East Africa into Southern Africa, with some populations crossing the Rift Valley (*); c Bathyergus (Ba.) and Georychus (Ge.) lineages diverge in South Africa; d Cryptomys (Cr.) diverges into two clades, one radiating predominantly in South Africa (1), and Fukomys spreading north into Southern, Central and West Africa (2); e formation of Lake Tanganyika; $\mathbf{f}$ later diversification of Fukomys clade in South-central Africa leaving disjunct populations in Central and West Africa (data adapted from Faulkes et al. 2004) 
and Early Miocene fossil faunas (Van Couvering and Van Couvering 1976). During this time, large-scale physical and climatic changes were also occurring in this part of Africa as a result of continental drift, leading to increased volcanism and the gradual formation of the African Rift Valley. These volcanic uplands and deep valleys, some of which eventually formed the great lakes of Africa, constitute a physical barrier for subterranean rodents. In addition, it is likely that the climatic and vegetative changes that indirectly resulted from the rifting process were of importance in determining the distribution and social evolution of the Bathyergidae. For example, estimates of the divergence of Georychus/Bathyergus from their common ancestor with Cryptomys/Fukomys (20-26 mya; Fig. 27.2c) coincide with the beginning of volcanism in the Kenya rift, and this may have favoured the expansion of these lineages into southern Africa, rather than to the north and west. At the same time, aridification of the Saharo-Arabian belt was beginning, and this would have further restricted the Bathyergidae to sub-Saharan Africa. The first fossil bathyergids are known from this period (Early Miocene) in both East Africa and Namibia, confirming these molecular-based estimates that southern Africa was also being colonized at this time. During the later Early and Middle Miocene the Cryptomys genus diverged into its two subclades (Cryptomys/Fukomys; at 12-17 mya; Fig. 27.2d). Again, this coincides with a critical period when rifting was progressing in the Kenya rift and also just beginning in the Western rift. While the Cryptomys clade appears to have speciated almost exclusively in South Africa, the Fukomys clade underwent a more extensive radiation, particularly in Zambia and Central Africa (Fig. 27.2e), resulting in a wide diversity of genetically divergent chromosomal forms (see below). This initial spread of Fukomys has left extant, but disjunct populations in central Africa as far west as Ghana (F. zechi), Nigeria (F. foxi) and Nigeria/Sudan/Uganda (F. ochraceocinereus). These species at the northern periphery of the bathyergid range form a basal clade in the Fukomys genus (Ingram et al. 2004; C.G. Faulkes and N.C. Bennett, unpublished data), and may represent relic populations from the initial radiation of Fukomys, isolated by the formation of tropical rainforest in the Congo Basin. If molecular timings are correct, then the initial radiation of Fukomys is coincident with the onset of volcanic activity in the adjacent Western rift. It is possible that the resulting environmental challenges brought about as climate and vegetation changed, may have influenced patterns of speciation and social elaboration. This period has previously been reported as a time of faunal turnover (Van Couvering and Van Couvering 1976). Further volcanism and formation of the East Africa rift during the Miocene appears to have almost completely isolated the populations of Heterocephalus and Heliophobius to the east, and restricted Cryptomys/Fukomys to the west of the Rift. Exceptions to this are a few populations of Fukomys whytei in western Tanzania, and Heliopho- 
bius found in Malawi, D.R. Congo and Zambia. The latter appear to have diverged before local rifting restricted their movement (Fig. 27.2f; Faulkes et al. 2004).

\section{4}

\section{Overview of the Six Genera}

Bathyergids exhibit considerable geographically structured morphological and genetical variation (see, e.g. Faulkes et al. 2004). In the past this fact triggered the description of many species and subspecies of bathyergids. Although this is not the place to revive the entire discussion about species concepts, it seems that the alternative species concepts cannot be neatly applied to bathyergids and subterranean rodents in general (see, e.g. Lessa 2000). By trying to box dynamic evolutionary processes in a static framework, we will inevitably be oversimplifying the complex relationships within certain taxa (e.g. Fukomys). We take the view that species limits should be established using multiple evidence, which takes into account variation at the molecular, cytogenetical and organismal levels. This section therefore highlights known polymorphism and divergence as observed in morphological, chromosomal, and molecular analyses to hint at both the validity of named forms and the possibility of finding additional, unrecognized forms among African mole-rats.

\subsection{1}

\section{The Eusocial Heterocephalus Rüppell, 1842}

Heterocephalus forms a monotypic genus. Despite genetic differences of $10.6 \%$ in cyt b between populations at the extremes of its range (Faulkes et al. 1997) and life history characteristics that seem to make Heterocephalus prone to speciation, Heterocephalus shows no morphological variation nor variation in chromosome number $(2 n=60$; George 1979; Capanna and Merani 1980).

\subsection{2}

\section{The Three Solitary Genera}

\section{Heliophobius Peters, 1846}

Currently only $H$. argenteocinereus is recognised as a valid species in this genus. Karyotypic variation ( $2 n=60-62$; George 1979; Scharff et al. 2001), high levels of cyt b sequence divergence (up to 13.3\%; Faulkes et al. 2004) 
and $12 S$ sequence divergence (7.3\%; Ingram et al. 2004) and morphological differences suggest that Heliophobius is actually polytypic.

\section{Bathyergus Illiger, 1811}

Two species are currently recognized with different karyotypes (Nevo et al. 1986): B. suillus $(2 n=56)$ and B. janetta $(2 n=54)$. However two recent independent studies have suggested that both species have a $2 n=54$ (C.G. Faulkes, unpublished data; J. Deuve and T.J. Robinson, unpublished data). Faulkes et al. 2004 reported relatively low levels of cyt $b$ sequence divergence (up to 5.6\%) and suggested the existence of a hybrid zone in an area where the species are sympatric. While Ingram et al. (2004) were unable to resolve interspecific relationships they suggested Bathyergus suillus might be more variable, warranting recognition of additional taxa.

\section{Georychus Illiger, 1811}

Although the accepted view is that Georychus just comprises one species: G. capensis, allozyme data (Nevo et al. 1987), mitochondrial RFLP data (Honeycutt et al. 1987) and high levels of mitochondrial sequence divergence (cyt b: up to 13.7\%; Faulkes et al. 2004; Ingram et al. 2004) all suggest the possibility of two species.

\section{5}

\section{Diversification in Social Mole-rats of the Genera Cryptomys Gray, 1864 and Fukomys (Kock, Ingram, Frabotta, Honeycutt and Burda 2006)}

\section{Cryptomys sensu lato}

Cryptomys sensu lato forms stable colonies with one reproductive female, one or more reproductive males and several non-reproductive animals that help with the care for the off-spring and maintenance of the colony. They are found in a variety of habitats, all of which are characterised by the presence of geophytes (staple food). Roots, bulbs and corms are harvested along extensive, anastomosing tunnel systems. The reproductive skew and other life history characteristics as well as differences in habitat are at the basis of intra- and intercolonial polymorphism in quantifiable traits (Rosevear 1969; Honeycutt et al. 1987; Burda et al. 1999; Bennett and Faulkes 2000; Janse Van Rensburg et al. 2004).

Therefore, it is no surprise that classifications of Cryptomys sensu lato based on morphological data (often subtle differences in a size variable, pelage colour or the extent of the headspot) show several inconsistencies. Accordingly there has been a great discrepancy in the number of 


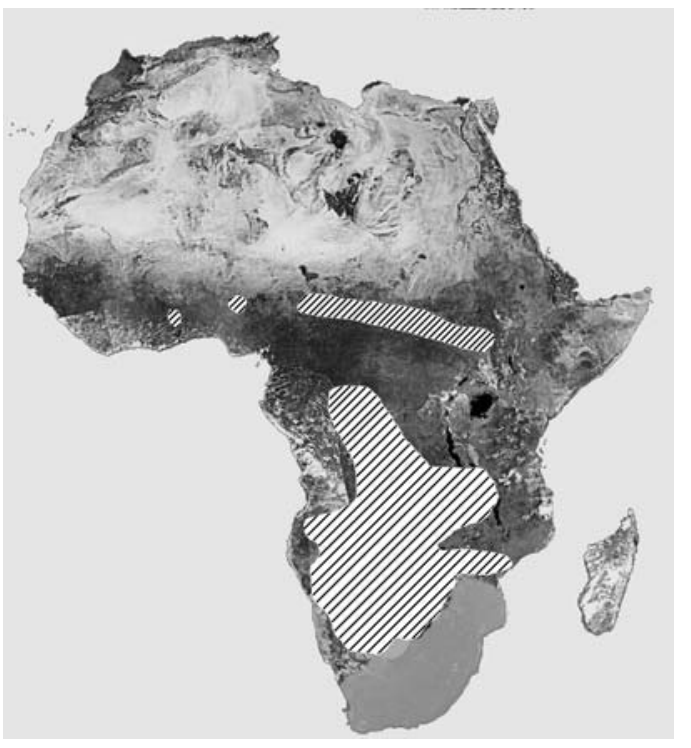

Fig. 27.3. Distribution map of Fukomys (hatched) and Cryptomys (grey). The main distribution of extant Fukomys is closely associated with mesic savannas North and South of the tropical rain forest belt

species recognised by different authors (Allen 1939; Ellerman et al. 1940; Roberts 1951; Ansell 1978; De Graaff 1981; Nowak 1991; Wilson and Reeder 2005).

Cryptomys sensu stricto is a South African radiation while Fukomys (synonym Coetomys; Kock et al. 2006) is widely distributed throughout the mesic and arid Savannahs (Fig. 27.3). The two genera show remarkably different evolutionary pathways. On the one hand Cryptomys sensu stricto is chromosomally conservative while showing deep DNA sequence divergences. Fukomys on the other hand, being chromosomally hypervariable, shows varying levels of sequence divergence (Van Daele et al., accepted; cf. below).

\section{Cryptomys Gray, 1864}

Cryptomys is a polytypic genus with at least six species. While the available data indicate it is chromosomally conservative $(2 n=54$; Nevo et al. 1986; Faulkes et al. 2004), the species richness of the group is supported by recent genetic studies. Ingram et al. (2004) recovered five monophyletic lineages, which they assigned to C. hottentotus, C. natalensis, C. nimrodi, $C$. holosericeus and C. anomalus, the latter from Pretoria. However, Faulkes et al. (2004) found two highly divergent populations around Pretoria, separated by only $30 \mathrm{~km}$ (using a subspecific nomenclature for all taxa, the Pretoria samples were assigned to C. hottentotus pretoriae and C.h. mahali). Several formally described races have not been thoroughly studied 
and therefore diversity could be much higher (Roberts 1951). However, one should take great care in assigning specimens or naming species as it has been hampered by the existence of many synonyms (there are 34 synonyms available for Southern African races of the C. hottentotus "superspecies" (De Graaff 1981) and vague type locality descriptions. Therefore a topotypical approach is required to avoid further confusion in the complicated taxonomy of this group.

\section{Fukomys (Kock, Ingram, Frabotta, Honeycutt and Burda 2006)}

Honeycutt et al. (1991) recognised six species: C. foxi (Thomas 1911) C. zechi (Matschie 1900) and C. ochraceocinereus (Heuglin 1864), which are distributed in the Sudanian savannahs and Cryptomys bocagei (De Winton 1897), C. damarensis (Ogilby 1838) and C. mechowii (Peters 1881) from the Zambezian region. Allozyme and karyological studies suggested the specific status of C. darlingi (Aguilar 1993), C. amatus (Macholán et al. 1998), C. kafuensis (Filippucci et al. 1994; Burda et al. 1999), C. anselli (Filippucci et al. 1994; Burda et al. 1999) and C. whytei (Chitaukali et al. 2001). Subsequently 11 new karyotypes were described from Zambia (Faulkes et al. 1997; Kawalika et al. 2001; Van Daele et al. 2004). Various other populations from the Zambezian region are known to be karyotypically different (PAAG Van Daele, unpublished data). Several of these may represent biological species. This is corroborated by studies showing considerable levels of allozyme divergence (Filippucci et al. 1994, 1997) and sequence diversity (Faulkes et al. 2004; Ingram et al. 2004; Van Daele et al., accepted).

Molecular sequence data show that a Sudanian clade is sister to six Zambezian clades (op. cit.). For the Sudanian clade, chromosomal ( $2 n=66 / 70$; Williams et al. 1983) and sequence data (Ingram et al. 2004) are scarce but suggest that at least the three named forms deserve specific status. Fukomys distributed in the Zambezian phytochorion show extreme chromosomal variability $(2 n=40-78)$, while levels of mitochondrial sequence divergence within and between subclades may vary considerably as detailed in Van Daele et al., accepted (Fig. 27.4). Remarkably the South Zambian phylogroup (micklemi clade: Fig. 27.4) containing F. micklemi, F. anselli, F. kafuensis and five other taxa with different karyotypes only show an average of $1.4 \%$ cyt b sequence divergence, similar to the widely distributed Southwestern Zambezian damarensis clade (five known karyotypes; $1 \%$ cyt b sequence difference). As opposed to these low levels of sequence divergence in the more arid parts of the Zambezian phytochorion, there appear to be high levels of genetic divergence between phylogroups from mesic regions (e.g. in the whytei clade).

Van Daele et al. (2004) noted that the distribution of the different karyotypical races correlates well with the extant river system configuration. They hypothesized that geomorphological changes and in particular river 


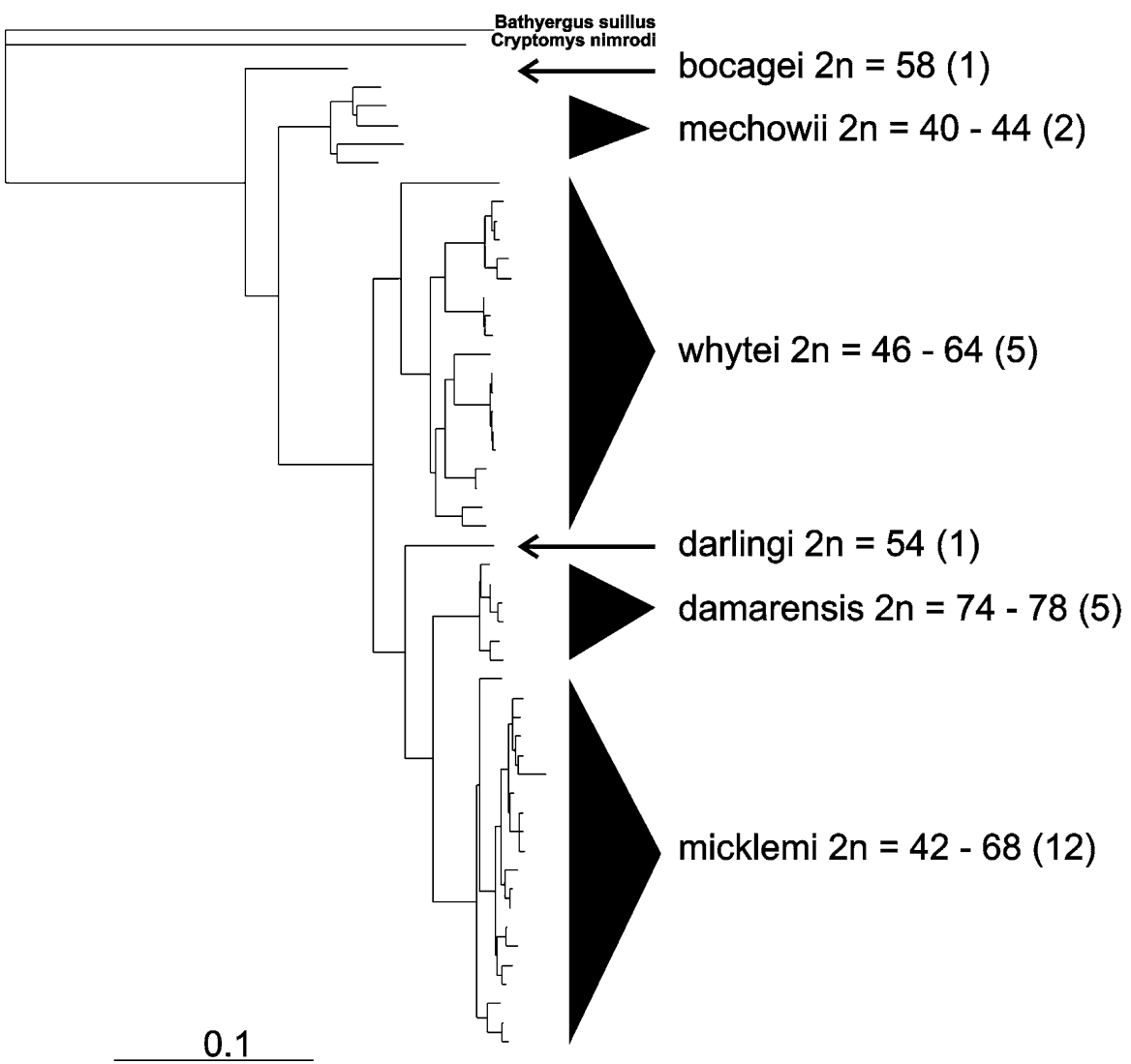

Fig. 27.4. Phylogenetic relationships of Fukomys haplotypes: Cyt b maximum-likelihood phylogeny under TIM $+\mathrm{I}+\Gamma$ model of evolution. Phylogenetic relationships of Fukomys haplotypes reveal six distinct subclades. The numbers in brackets refer to the number of known chromosomal races. The scale bar indicates the number of substitutions per site (data adapted from Van Daele et al., accepted)

system dynamics in recent geological times (from the Neogene on) have played an important role in the chromosomal diversification and would have provided ample opportunities for speciation (including vicariance and allopatric processes) to occur. The phylogeographic history of Zambezian Fukomys would then have been driven by the joining and fragmentation of precursors of extant rivers driven by crustal flexion (both down warping and uplifting) and associated climatic shifts. This is corroborated to a large extend by estimates of divergence dates (Van Daele et al., accepted; Fig. 27.5). 


\section{6}

\section{Prospects (for Phylogenetic Studies and Beyond)}

In addition to further molecular phylogenetic sequence analysis, morphometrical, ethological and detailed chromosomal studies using differential staining techniques are required to create a robust phylogenetic framework for examining intrageneric relationships and the identification of cryptic species. Differential patterns of chromosomal and molecular genetic evolution and speciation should be further explored using a multidisciplinary approach, starting with a topotypical sampling strategy. In an interesting overview of future directions of research on subterranean rodents, Lessa (2000) stresses that a phylogenetic framework is not only an important prerequisite for understanding macroevolutionary processes but also provides the necessary context to discuss the structure and function and the relative importance of adaptation. We believe that in particular Fukomys provides an evolutionary model that could yield fruitful results in the future, ultimately enriching evolutionary theory. Further DNA sequencing implies a better knowledge of gene structure, but it is an understanding of gene function that will enhance molecular genetic insight into evolutionary processes of speciation and adaptation. Using, e.g. microarray technology, Fukomys will undoubtedly be instrumental in the exploration of differential ageing patterns (Dammann and Burda 2006). Exemplatory at the organismal level are studies which have explored how morphometrical variation maps on phylogenetic trees. Preliminary data obtained from a geometric morphometrical analysis of the ventral side of the cranium of a number of closely related chromosomal races belonging to the F. micklemi phylogroup suggest that during raciation small localized shape changes (shape changes of so-called non-uniform origin; Zelditch et al. 2004) could modify the integration of structures with shifts in functionality. As expected, these shape changes do not seem to follow the cladogenetic sequence of events as depicted by a cyt b phylogeny (Van Daele et al. 2006). This fact could be further exploited to understand how either plastic responses to immediate ecological conditions (cf. Patton and Brylski 1987) and/or changes in shape associated with digging and chewing modes (reviews by Lessa 1990; Stein 2000) appear time and again in the evolution of subterranean lineages. Transposed on a phylogenetic framework morphometrical changes per se and other morphological characters (that may map better on phylogenetic trees) could help to elucidate the sequence and nature of morphological adaptation within the constraints set by the subterranean environment. 


\section{PLIOCENE}

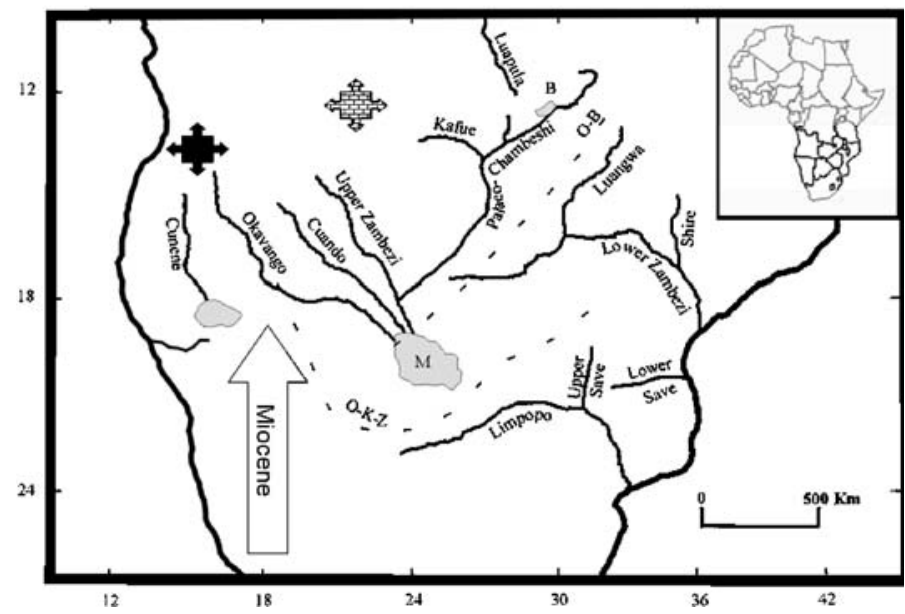

\section{EARLY PLEISTOCENE}

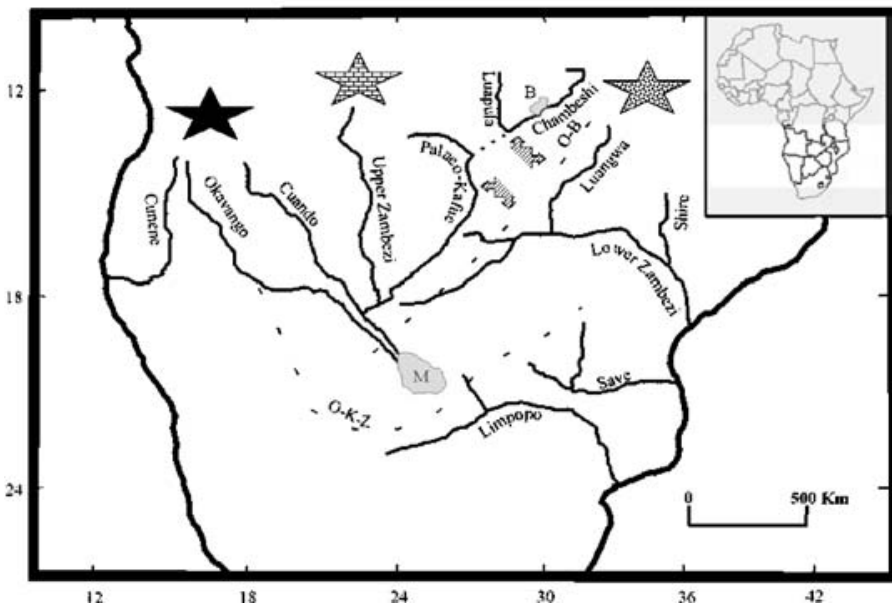

Fig. 27.5. Phylogeographic trends in Zambezian Fukomys estimated from Cyt b sequence differences using nonparametric rate smoothing and penalized likelihood methods as implemented in r8s (Sanderson 1997, 2002) (data adapted from Van Daele et al., accepted). The general distribution of the extant Fukomys clades would have been determined in the Holocene, when the riversystem configuration became similar to today's situation. (Drainage system evolution in South-Central Africa. Figure modified after Du Toit (1933), Moore and Larkin (2001) and Cotterill (2003). M Paleo-lake Makgadikgadi; $B$ Lake Bangweulu; $O K Z$ Ovamboland - Kalahari - Zimbabwe axis of crustal flexuring and $O B$ Okavango - Bangweulu axis of crustal flexuring) 


\section{LATE PLEISTOCENE}

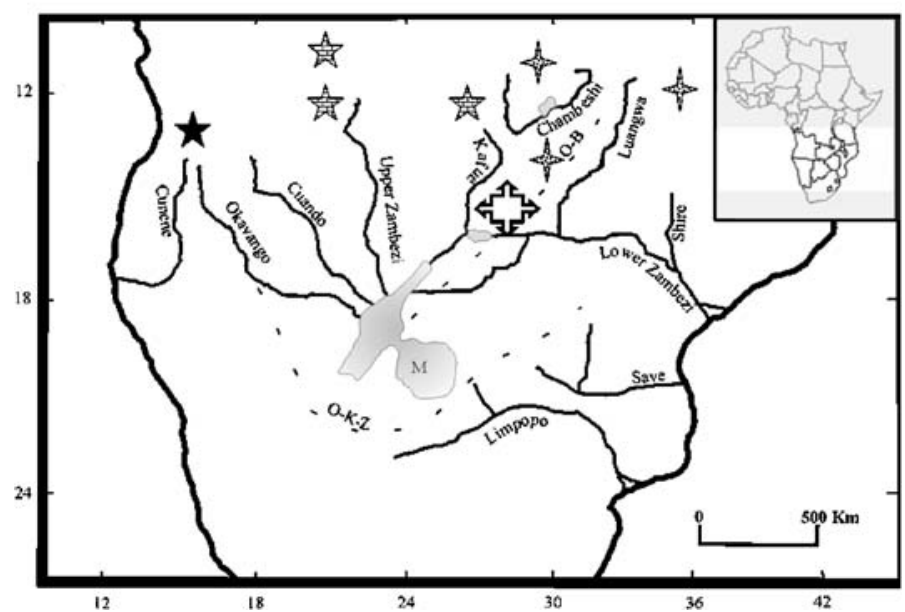

\section{HOLOCENE}

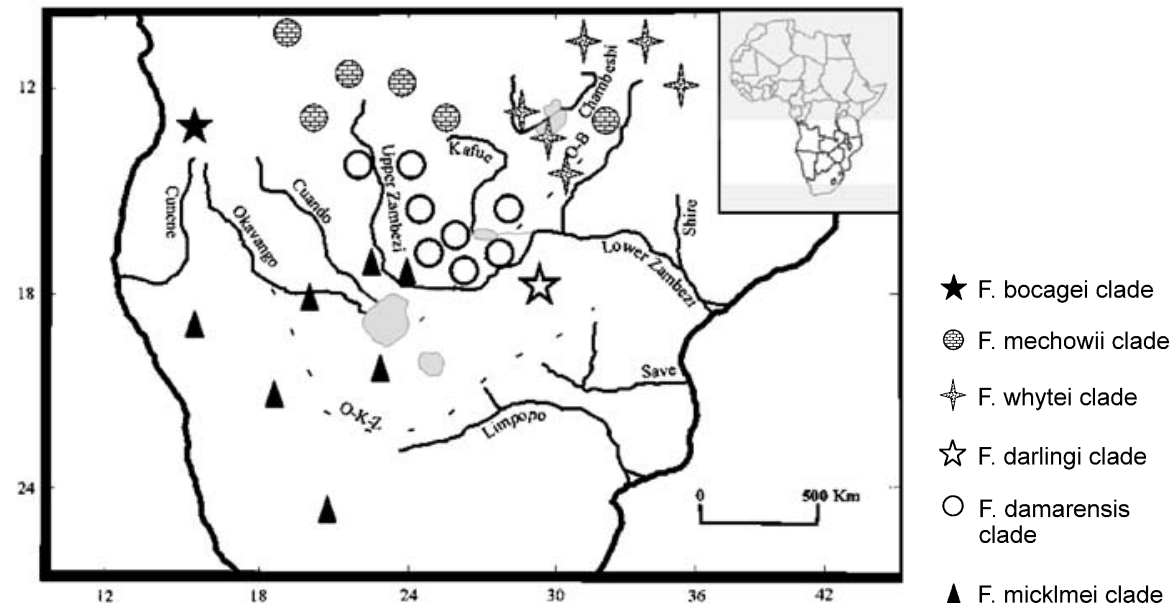

Fig. 27.5. Legend.

Divergence time estimates suggest a Pliocene origin of Zambezian Fukomys. The common ancestor of Fukomys would have colonized the lower latitudes dispersing along shifting vegetation belts during the late Miocene. As the Sudanian lineage (North of the tropical rainforest belt) became gradually isolated from the Zambezian lineage, the latter radiated in the Zambezian savanna belt.

A first divergence occurred in the Early Pliocene, eventually giving rise to the basal Zambezian clade including F. bocagei, which dispersed throughout Angola.

The common ancestor of the other Zambezian clades would have had ample opportunity during the Pliocene to disperse along the watershed between the precursors of the headwaters of the Zambezi and Zaire Rivers.
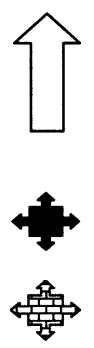
Fig. 27.5. Legend. (continued)

During the Late Pliocene the giant mole-rat or F. mechowii lineage split from the lineage containing the smaller mole-rats, which diverged in a northern and southern lineage.

The Pleistocene is characterized by several consecutive radiation bursts, driven by the dynamic interaction of a fluctuating climate with associated geomorphological and vegetational changes. Coincident with reconfigurations of the major riversystem during the Pleistocene all major lineages of small mole-rats emerged. While the radiation of the northern lineage seems to be coupled to reconfigurations of the headwaters of the Luapula river during the Early Pleistocene, the divergence time estimates of the radiation of the southern clades correlates with the formation of the Kafue and Zambezi rivers in the South-Central Zambezian region during the Late Pleistocene. F. damarensis, being the most derived taxon, seems to have diverged from the F. micklemi clade after the final formation of the Zambezi, radiating around the

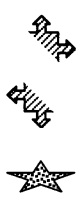
shores of Paleo-lake Makgadikgadi.

Acknowledgements. We would like to thank the following people for assistance in collecting specimens or sending samples - we thank H. Burda, C. Ingram, V. Katanekwa, M. Kawalika, E. Sikaboa, S. Stoops as well as the Zambian Wildlife Authority, Lusaka for issuing export permits. We are grateful to an anonymous reviewer for valuable comments.

\section{References}

Aguilar GH (1993) The karyotype and taxonomic status of Cryptomys-hottentotus-darlingi (Rodentia, Bathyergidae). S Afr J Zool 28:201-204

Allard MW, Honeycutt RL (1992) Nucleotide-sequence variation in the mitochondrial 12s ribosomal-RNA gene and the phylogeny of African mole-rats (Rodentia, Bathyergidae). Mol Biol Evol 9:27-40

Allen GM (1939) A checklist of African mammals. Bull Mus Comp Zool Harvard Coll $83: 425-433$

Ansell WFH (1978) The mammals of Zambia. National Parks and Wildlife Services, Chilanga, Zambia

Bennett NC, Faulkes CG (2000) African mole-rats: ecology and eusociality. Cambridge Univ Press, Cambridge

Burda H, Zima J, Scharff A, Macholán M, Kawalika M (1999) The karyotypes of Cryptomys anselli sp nova and Cryptomys kafuensis sp nova: New species of the common mole-rat from Zambia (Rodentia, Bathyergidae). Int J Mamm Biol 64:36-50

Burda H, Honeycutt RL, Begall S, Locker-Grütjen O, Scharff A (2000) Are naked and common mole-rats eusocial and if so, why? Behav Ecol Sociobiol 47:293-303

Capanna E, Merani MS (1980) Karyotypes of Somalian rodent populations.1. Heterocephalus glaber Ruppell, 1842 (Mammalia, Rodentia). Mon Zool Ital Suppl 13:45-51

Chitaukali WN, Burda H, Kock D (2001) On small mammals of the Nyika Plateau, Malawi. IRD Editions, Collection colloques et séminaires, Paris, pp 415-426

Cotterill FPD (2003) Geomorphological influences on vicariant evolution in some African mammals in the Zambezi Basin: some lessons for conservation. Proceedings of the 
Ecology and Conservation of Mini-antelope: An International Symposium on Duiker and Dwarf Antelope in Africa. Filander Verlag, Fürth, pp 11-58

Dammann P, Burda H (2006) Sexual activity and reproduction delay ageing in a mammal. Curr Biol 16:R117-R118

De Graaff G (1981) The rodents of Southern Africa. Butterworths, Durban

Du Toit AL (1933) Crustal movement as a factor in the geographical evolution of South Africa. S Afr Geogr J 6:14-20

Ellerman JR, Hayman RW, Holt GWC (1940) The families and genera of living rodents. Trustees of the British Museum (Natural History), London

Ellerman JR, Morrison-Scott TCS, Hayman RW (1953) Southern African mammals, 1758 to 1951: a reclassification. Trustees of the British Museum (Natural History), London

Faulkes CG, Bennett NC, Bruford MW, O’Brien HP, Aguilar GH, Jarvis JUM (1997) Ecological constraints drive social evolution in the African mole-rats. Proc R Soc Lond B 264:16191627

Faulkes CG, Verheyen E, Verheyen W, Jarvis JUM, Bennett NC (2004) Phylogeographical patterns of genetic divergence and speciation in African mole-rats (Family: Bathyergidae). Mol Ecol 13:613-629

Filippucci MG, Burda H, Nevo E, Kocka J (1994) Allozyme divergence and systematics of common mole-rats (Cryptomys, Bathyergidae, Rodentia) from Zambia. Int J Mamm Biol 59:42-51

Filippucci MG, Kawalika M, Macholán M, Scharff A, Burda H (1997) Allozyme differentiation and systematic relationship of Zambian giant mole-rats, Cryptomys mechowi (Bathyergidae, Rodentia). Int J Mamm Biol 62:172-178

George W (1979) Conservatism in the karyotypes of two African mole-rats (Rodentia, Bathyergidae). Int J Mamm Biol 44:278-285

Golding GB, Strobeck C (1983) Increased number of alleles found in hybrid populations due to intragenic recombination. Evol 37:17-29

Grant PR, Grant BR (1997) Genetics and the origin of bird species. Proc Natl Acad Sci USA 94:7768-7775

Harrison RG (1993) Hybrids and hybrid zones. In: Harrison RG (ed) Hybrid zones and the evolutionary process. Oxford Univ Press, New York, pp 3-12

Honeycutt RL, Edwards SV, Nelson K, Nevo E (1987) Mitochondrial-DNA variation and the phylogeny of African mole-rats (Rodentia, Bathyergidae). Syst Zool 36:280-292

Honeycutt RL, Nelson K, Schlitter DA, Sherman PW (1991) Genetic variation within and among populations of the naked mole-rat: evidence from nuclear and mitochondrial genomes. In: Sherman PW, Jarvis JUM, Alexander RD (eds) The biology of the naked mole-rat. Princeton Univ Press, Princeton, NJ, pp 195-208

Huchon D, Douzery EJP (2001) From the old world to the new world: a molecular chronicle of the phylogeny and biogeography of Hystricognath rodents. Mol Phyl Evol 20: 238-251

Ingram CM, Burda $\mathrm{H}$, Honeycutt RL (2004) Molecular phylogenetics and taxonomy of the African mole-rats, genus Cryptomys and the new genus Coetomys Gray, 1864. Mol Phyl Evol 31:997-1014

Janecek LL, Honeycutt RL, Rautenbach IL, Erasmus BH, Reig S, Schlitter DA (1992) Allozyme variation and systematics of African mole-rats (Rodentia, Bathyergidae). Biochem Syst Ecol 20:401-416

Janse Van Rensburg L, Chimimba CT, Van Der Merwe M, Schoeman AS, Bennett NC (2004) Relative age and reproductive status in Cryptomys hottentotus pretoriae (Rodentia: Bathyergidae) from South Africa. J Mammal 85:1225-1232

Jarvis JUM (1981) Eusociality in a mammal - cooperative breeding in naked mole-rat Heterocephalus glaber colonies. Science 212:571-573 
Jarvis JUM, Bennett NC (1990) The evolutionary history, population biology and social structure of African mole-rats: Family Bathyergidae. In: Nevo E, Reig OA (eds) Evolution of subterranean mammals at the organismal and molecular levels. Wiley-Liss, New York, pp 97-128

Jarvis JUM, Bennett NC (1993) Eusociality has evolved independently in two genera of bathyergid mole-rats - but occurs in no other subterranean mammal. Behav Ecol Sociobiol 33:253-260

Kawalika M, Burda H, Brüggert D (2001) Was Zambia a cradle of the genus Cryptomys (Bathyergidae, Rodentia)? African small mammals. IRD Editions, Collection colloques et séminaires, Paris, pp 253-261

Kock D, Ingram CM, Frabotta LJ, Honeycutt RL, Burda H (2006) On the nomenclature of Bathyergidae and Fukomys n. gen. (Mammalia : Rodentia). Zootaxa 51-55

Lavocat R (1978) Rodentia and Lagomorpha. Evolution of African mammals. Harvard Univ Press, Cambridge, Mass., pp 69-89

Lessa EP (1990) Morphological evolution of subterranean mammals: integrating structural, functional, and ecological perspectives. In: Nevo E, Reig OA (eds) Evolution of subterranean mammals at the organismal and molecular levels. Wiley-Liss, New York

Lessa EP (2000) The evolution of subterranean rodents: a synthesis. In: Lacey EA, Patton JL, Cameron G (eds) Life underground: the biology of subterranean rodents. Univ of Chicago Press, Chicago, pp 389-420

Macholan M, Scharff A, Burda H, Zima J, Grütjen O (1998) The karyotype and taxonomic status of Cryptomys amatus (Wroughton, 1907) from Zambia (Rodentia, Bathyergidae). Int J Mamm Biol 63:186-190

Moore AE, Larkin PA (2001) Drainage evolution in south-central Africa since the break-up of Gondwana. S Afr J Geol 103:47-68

Nedbal MA, Allard MW, Honeycutt RL (1994) Molecular systematics of hystricognath rodents: evidence from the mitochondrial 12S rRNA gene. Mol Phyl Evol 3:206-220

Nevo E, Capanna E, Corti M, Jarvis JUM, Hickman GC (1986) Karyotype differentiation in the endemic subterranean mole-rats of South-Africa (Rodentia, Bathyergidae). Int J Mamm Biol 51:36-49

Nevo E, Ben-Shlomo R, Beiles A, Jarvis JUM, Hickman GC (1987) Allozyme differentiation and systematics of the endemic subterranean mole-rats of South-Africa. Biochem Syst Ecol 15:489-502

Nowak R (1991) Walker's mammals of the world. Johns Hopkins Univ Press, Baltimore

Patton JL, Brylski PV (1987) Pocket gophers in alfalfa fields - causes and consequences of habitat-related body size variation. Am Nat 130:493-506

Roberts A (1951) The mammals of South Africa. Trustees of 'the mammals of South Africa' book fund, Johannesburg

Rosevear DR (1969) Rodents of West Africa. Trustees of the British Museum (Natural History), London

Ruedi M, Smith MF, Patton JL (1997) Phylogenetic evidence of mitochondrial DNA introgression among pocket gophers in New Mexico (family Geomyidae). Mol Ecol 6: 453-462

Sanderson MJ (1997) A nonparamateric approach to estimating divergence times in the absence of rate constancy. Mol Biol Evol 1218-1231

Sanderson MJ (2002) Estimating absolute rates of molecular evolution and divergence times: A penalized likelihood approach. Mol Biol Evol 19:101-109

Scharff A, Macholan M, Zima J, Burda H (2001) A new karyotype of Heliophobius argenteocinereus (Bathyergidae, Rodentia) from Zambia with field notes on the species. Int J Mamm Biol 66:376-378 
Stein BR (2000) Morphology of subterranean rodents. In: Lacey EA, Patton JL, Cameron $\mathrm{G}$ (eds) Life underground: the biology of subterranean rodents. Univ Chicago Press, Chicago, pp 19-62

Steinberg EK, Patton JL (2000) Genetic structure and the geography of speciation in subterranean rodents: opportunities and constraints for evolutionary diversification. In: Lacey EA, Patton JL, Cameron G (eds) Life underground: the biology of subterranean rodents. Univ Chicago Press, Chicago, pp 301-331

Van Couvering JAH, Van Couvering JA (1976) Community evolution in East Africa during the late Cenozoic. In: Isaac G, McCown ER (eds) Human origins: Louis Leakey and the East African evidence. WA Benjamin, Menlo Park, California, pp 155-207

Van Daele PAAG, Dammann P, Meier JL, Kawalika M, Van De Woestijne C, Burda H (2004) Chromosomal diversity in mole-rats of the genus Cryptomys (Rodentia : Bathyergidae) from the Zambezian region: with descriptions of new karyotypes. J Zool Lond 264:317326

Van Daele PAAG, Verheyen E, Corkery I, Adriaens D (2006) Trends in skull morphology in relation to differential molecular evolution in African mole-rats of the chromosomally hyperdivers genus Fukomys (Bathyergidae, Rodentia) from the Zambezian region. Ital J Mammal (n.s.) suppl.:143

Van Daele PAAG, Verheyen E, Adriens D, Brunain M (accepted) Cytochrome b sequence analysis reveals differential molecular evolution in African mole-rats of the chromosomally genus Fukomys (Bathyergidae, Rodentia) from the Zambezian region. Mol Phyl Evol

Van Zinderen Bakker EM (1967) The 'arid corridor' between southwest Africa and the Horn of Africa. In: Van Zinderen Bakker EM (ed) Paleoecology of Africa, vol 2. AA Balkema, Amsterdam pp 76-69

Walton AH, Nedbal MA, Honeycutt RL (2000) Evidence from intron 1 of the nuclear transthyretin (Prealbumin) gene for the phylogeny of African mole-rats (Bathyergidae). Mol Phyl Evol 16:467-474

Williams SL, Schlitter DA, Robbins LW (1983) Morphological variation in a natural population of Cryptomys (Rodentia: Bathyergidae) from Cameroon. Ann Mus R Afr Centr Sc Zool 237:159-172

Wilson DE, Reeder DM (2005) Mammal species of the world. Johns Hopkins Univ Press, Baltimore

Wood AE (1985) The relationships, origin, and dispersal of the hystricognathous rodents. In: Evolutionary relationships among rodents: a multidisciplinary analysis. NATO ASI Series, New York, pp 475-513

Zelditch ML, Swiderski DL, Sheets HD, Fink WL (2004) Geometric morphometrics for biologists: a primer. Elsevier Academic Press, London 